\title{
Machine Translation in Foreign Language Learning Classroom-Learners' Indiscriminate Use or Instructors' Discriminate Stance
}

\author{
Xiaomin Zhu \\ Correspondence: Xiaomin Zhu, School of Foreign Languages, Yunnan Normal University, Kunming, P. R. China. \\ Received: Sep. 27, 2020 \\ Accepted: Oct. 12, 2020 \\ Online Published: Oct. 15, 2020 \\ doi:10.5430/elr.v9n4p1 \\ URL: https://doi.org/10.5430/elr.v9n4p1
}

\begin{abstract}
The use of machine translation (MT) tools in language learning classroom is now omnipresent, which raises a dilemma for instructors because of two issues, language proficiency and academic integrity, caused by that fact. However, with the unstoppable development and irresistible use of MT in language learning, rather than entangling with using it or banning it, it is more significant to figure out why learners turn to MT in spite of the prohibition from their instructors and how can instructors guide learners to use it appropriately. Consequently, this paper reviews articles with regard to the reason why learners turn to MT, the practical use of MT in learners' writing, and some pedagogical solutions for making peace with MT in language learning classroom respectively. Implications can be garnered like that a course for learners of how to use MT tools properly should be included in the curriculum design, and simultaneously, the holistic understanding of these overwhelmingly fast-developed technology tools for instructors should be a part of teachers' self-development, since instructors without knowledge said technology tools can not fully motivate language learners and implement the pedagogical solutions offered.
\end{abstract}

Keywords: machine translation (MT), foreign language learning, pedagogical solutions

\section{Introduction}

First proposed in 1949 in a memorandum from Warren Weaver, a British crystallographer, the idea of machine translation (MT), which was initially for the use of war-time cryptography techniques, statistical analysis, Shannon's information theory, and the exploration of the underlying logic and universal features of language (Hutchins \& Sommers, 1992), is now widespread availability not only to professional translators to dispose some tedious and repetitive source texts like commercial and business transaction, legal documentation, industrial patents and so forth, but also to students for their foreign language assignments. Concerns and debates regarding the use of MT in language learning follows the improvement of the capabilities of MT. Instructors explicitly dissuade students' use of MT with the anxiety of academic honesty violations and increased dependency on MT, while students surreptitiously consult online translators because of its rapidity, simplicity of results and amelioration of accuracy (Guenette, 2013). Actually, the advancement, pervasiveness and versatility of MT are irresistible nowadays. Policies that turn MT into a taboo stand directly in opposition to the gist of aiding a student become "a 21 st Century skilled learner" recommended by the American Council on the Teaching of Foreign Language (ACTFL) (ACTFL, 2011). Therefore, studies on why learners use MT programs and how they interact with them (White \& Heidrich, 2013), what instructors can do to equip their students to use the MT in an educationally and interculturally respectful manner (Ducar \& Schocket, 2018) and practical MT use in learners' writing (García \& Pena, 2011) seem to be more significant for us to confront the challenge of learners' indiscriminate use of MT.

\section{Literature Review}

\subsection{Machine Translation}

Impressive progress has been witnessed in the realm of Machine Translation (MT), since its first debut in Warren Weaver's memorandum. Nowadays, MT tools are widely used available for many users or domains, but the wrong translation productions are intolerable, so that the human corrector are introduced to the process of post-editing. Aiming to diminish the human effort of post-editing to produce better translations, interactive machine translation (IMT) (Barrachina et al., 2009; Casacuberta et al., 2009; Foster et al.,1997) emerged as one of the most attractive strategies to solve the problem. In the development of MT, researchers have found that reordering errors and lexical and syntactic ambiguity are barriers that affect the quality of final translation. To address these obstacles, a large number of MT approaches have been developed over the years, among which the use of methodologies based on 
linguistics has resulted in the family of Rule-Based Machine Translation (RBMT) (Moussallem et al., 2018). However, the drawback, reliance on manually crafted rules, has prevented the easy development of new translation modules for different language. Then, a standard Phrase-Based Statistical Machine Translation (BP-SMT) system (Koehn et al., 2003b) and Example-Based Machine Translation (EBMT) were developed to deal with the scalability issues in RBMT (Moussallem et al., 2018). In recent years, neural machine translation (NMT), a novel corpus-based technology, emerged as the state-of-the-art in MT, in which the translations are generated solely by neural networks (Kazemi et al., 2017). The research and development of MT will never stop, and is unstoppable, indicating that the use of MT in every domains including language learning is also irrevocable.

\subsection{Machine Translation in Foreign Language Learning and Teaching}

With the popularization of personal computers and technological devices, the past 70 years saw the notable progress in the realm of machine translation after originally being proposed in Weaver's memorandum. In many previous studies on MT and language learning (García \& Pena, 2011; Correa, 2011, 2014; Kazemzadeh \& Kashani, 2014), researchers found that a majority of students have admitted that they had consulted online translators when doing their foreign language (FL) assignments although their instructors explicitly asked them not to. Since the development of MT and the use of it in language learning are irreversible, there is no need to intertwine with using it or banning it. Rather, it is beneficial for us to figure out why we use it and how to use it effectively.

With the overwhelmingly fast development of MT technology, researchers have been aware of the use of MT in language learning. Several studies focusing on MT in language learning have been conducted, among which the study having been carried out by Ignacio García and María Isabel Pena (2011), rather than inquiring to the MT as a language learning tool concentrating on its use by advanced learners like many other research, have paid attention to its use by beginners and early intermediate learners. With the purpose of figuring out whether "MT can be considered a suitable activity for developing writing skills in L2 of beginner/early intermediate language learners"(p.473), tests involving students of Spanish as participants were done at the School of Humanities and Languages in the University of Western Sydney. Two groups of participants were engaged with this test, the first group with 9 participants (six female, three male) being beginners as Level 1, while seven participants (four female, three male) being early intermediate level as Level 2 at the second group. In order to "discover whether students would communicate better and learn more if they wrote directly in Spanish or with the help of an MT draft"(p.474), two groups of participants were required to respond to a prompt that was at the same notional difficulty with 50 words at Level 1 and 100 at Level 2 using email communication. Two tasks, the first, a common task for both level, and the second, level-specific, were timed 15 minutes each. The tests, in which participants were asked to respond to one of the prompts directly in L2 and to the other in English first, using the MT Tradukka interface, a free application released in 2009, were screen-recorded by using BB FlashBack Pro 2.7.3 with regard to the cursor movements and the keyboard log. Having completed the test, two questions were raised for participants to respond "(1) Do you think you did better writing directly in Spanish or using machine translation?" aiming to "check whether there was correspondence between the perceptions of participants and our findings about the writing as a product", "(2) What do you think about using machine translation for writing into Spanish: would it help you express yourself better in Spanish? Would it help or hinder the process of learning Spanish?" (p.476) which was aimed at finding out the participants' thought of the activity, and figuring out "the possible correlations between the perceptions of participants and our findings about the writing as a process" (p.476). Conclusions can be drawn like that the findings of this study showed that MT do help beginner learners in their writing not only with writing more words but also with less effort. However, one thing needs to be conceded is that although MT assists the writing process, students' more exposure to target language may not happen this way. Several participants expressed their concerns of depending on MT despite the fact that MT aids them "to write faster with fewer mistakes" (p.485).

Kelsey D. White and Emily Heidrich (2013), from university of Wisconsin-Madison, conducted a research to figure out the reason of using MT from two perspectives, strategies before, during and after translation and beliefs about interactions with MT, with three research questions. Eighteen participants, intermediate learners of German chosen from one intact class, were involved in this study in which both quantitative and qualitative methods were employed. In the beginning questionnaire, demographic and background information were collected, such as English as their L1, German as FL, using web-based machine translation (WBMT) for an average of $27.7 \%$ of FL assignments and so forth. In the following translation task, students were required to write a paragraph in English describing a picture without knowing that their writing would be used in the following translation task. Having completed the writing task, students were informed that their composition would be translated into German using WBMT, but they were offered the option to edit their work so as to make it more appropriate for accurate translation. A further option to edit WBMT output was also offered to students. This study ended up with a final questionnaire about students' feeling 
about their interaction with this WBMT tool. Following, semi-scripted interviews involving 5 participants of the 18 were conducted face-to-face to further discuss their beliefs about WBMT and strategies used during the tasks with WBMT. Conclusion was drawn like that both students' beliefs and strategies are closely interconnected. The reason why many students continue to use WBMT in spite of its prohibition is that the use of WBMT can ensure them with linguistic accuracy at the cost of sophistication, complexity and expressing their own voice, which was indicated in the pre-task questionnaire survey.

In the article Machine translation and the L2 classroom: Pedagogical solutions for making peace with Google translate published in 2018, Cynthia Ducar and Deborah Houk Schocket analyzed the strengths and limitations of Google Translation (GT), a MT tool widely used, and proposed many valuable pedagogical suggestions. First launched in 2006, GT has made great progress not only in translating texts instantaneously, but also in listening, speaking and reading, which made it multifaceted. GT excels at conjugating verbs which enables lower-lever students to generate complex verb tenses that have not yet been studied, spelling and translating high-frequency idioms. However, pragmatical inaccuracy and intercultural ignorance when translating are the limitations that GT fails to break. When it comes to the pedagogical implications, many invaluable proposals were put forward by authors. It is essential to clearly and repeatedly inform students who grew up in a digital environment that "inputting data into GT and reproducing those results patently violates the code of academic conduct" (p.788). Additionally, motivating learners by "prioritizing learner-centered instruction; offering a challenging, content-infused curriculum; engaging students in project- and community-based learning" (p.789) can promote their awareness of language learning and involve them more in language learning so that their tendency to depend on MT may decrease. In order to expose learners to the pitfalls of MT, some pedagogical activities can be designed for students, such as, proposed by author, "translating a popular song from English into the target language and then comparing students' version with GT's" (p.789), which can make it clear evidence that translations are not simply "substituting words" and not rarely "verbatim reproduction of the original text" (p.789). In 2017, a notion of technology-facilitated language learning put forward in ACTFL's Statement on the Role of Technology in Language Learning was that "standard-based, instructor-designed, learner-centered, and aimed at developing proficiency in the target language through interactive, meaningful, and cognitively engaging learning experiences" (ACTFL, 2017a). What can be inferred from is that in the age of information and technology, advanced tools for language learning is not merely GT, Microsoft Word, WordReference (WR), a powerful online dictionary, and Linguee, a Web site that combines a dictionary with a search engine, can provide alternatives for instructors and learners to choose. Also, corpora databases can definitely not be neglected. Learners' proficiency development can not be achieved in vocabulary, expressions, grammar and syntax respectively without the engagement with texts and contexts. Some critical and social reading tools like InsertLearning and eComma can, to some extent, provide solutions to this problem by offering "appropriately leveled authentic materials on high-interest topics" (p.791). When instructors design classroom pedagogies to help students appropriately consult MT, there are several key points summarized by authors that they must bear in mind, including “(1) evaluate students' own knowledge of the available and emerging tools, (2) directly teach learners how to use appropriate technology responsibly, (3) review their beliefs about students' use of supportive technologies, (4) familiarize themselves with their institution's policies on academic honesty, and (5) decide how they intend to act and react when such policies are violated" (p.793), which are all significant and imperative for the future implementation of language teaching and learning.

\section{Implications}

When it comes to whether MT is helpful to language learning, research mentioned above have confirmed that it did make contribution to language learning more or less. What we can do is to leverage the use of MT in language learning, since MT now is considered as the fifth macro-skill to complete the other four, speaking, listening, reading and writing. As Krawer (1995) demonstrates that it is not the software itself, but the user of that software who determine the utility of machine translation systems. So, it is never overemphasized the importance of guiding learners how to use MT appropriately (White \& Heidrich, 2013; Ducar \& Schocket, 2018; Williams, 2006; Correa, 2014; García \& Pena, 2011). A course related to teaching students to use MT tools in a responsible way should be included in the curriculum design across the upper elementary, secondary, and postsecondary spectrum with a beginning questionnaire used to estimate students' own knowledge of the available and novel technology tools for language learning in their first lesson, so that instructors can promote, rather than circumvent, students' progress to more sophisticated language proficiency with the help of MT (Ducar \& Schocket, 2018). As aforementioned, the use of MT tools like GT can be mitigated by fully introducing the other technology tools assisting language learning, such as Microsoft Word, WR, Linguee, InsertLearning and eComma, and so forth, according to the specific pedagogical needs. Since instructors' attitudes and beliefs play a vital role in the use of MT tools in language 
learning, it is necessary to evaluate educators' own knowledge about these accessible and emerging technology tools, because when guiding students to use them appropriately, instructors without understanding said technology tools can not truly leverage the advantages of these tools and help students to achieve their further proficiency in language learning. That is to say, the most urgent thing to do is not to focus on how to instruct learners to properly use MT tools but to figure out what instructors' stances on and knowledge about MT tools used in language learning.

Actually, in the research conducted by García and Pena (2011), language learners have showed their concerns that although MT helps them to communicate better or with less effort, there is also the risk of making them dependent on MT and becoming lazy. For the students who are truly dedicated themselves to acquiring a foreign language, they can be aware that the use of MT can not lead them to what they want, so they will use it cautiously and accordingly. But there are still many students to consult MT tools when doing their FL assignment. One reason may be that the assignment appointed by instructors seems so overwhelmingly daunting (Ducar \& Schocket, 2018) that they can only turn to MT. Therefore, the assignments should target the appropriate level of production as recommended in ACTFL Can-Do-Statements (ACTFL, 2017b) and evaluations and assessments can be shifted to focus on important content, meaningful communication and linguistic and cultural growth from grammatical accuracy alone. Also, clear instructions made by educators before starting the assignment can make it easier for learners to do. The other reason may be related to the motivation of learners. Helping learners autonomously communicate and further their proficiency seems more crucial than simply finish their assignments. It is beneficial to advocate the notion that learning foreign language as a $21^{\text {st }}$-century skill and personal goals is a valuable investment in their own language development, because success in careers across a range of domains attributes to the well-developed skills in language (Strauss, 2017). Moreover, the information that graduates majoring in Foreign languages, Literatures, and Linguistics were the fewest underemployed in 2016 (Newton, 2018) can ultimately motivate our learners.

\section{Conclusion}

There is no doubt that the emergence and development of MT and its pervasiveness in the language learning classroom raises concerns about both language proficiency and academic honesty for instructors. Since the use of MT in language learning do further learners' language proficiency, which was revealed in many researches related to the use of MT in language learning, paying attentions to guiding learners appropriately to use MT seems more significant to the future pedagogy. Before that, the evaluation of instructors' stances on the use of MT in language learning classroom and their own knowledge about technological tools for language learning is a top priority. Instructors without understanding of these fast-developed technology tools may not be able to guide their students well. When we advocate that a course of using MT tools in language learning classroom should be included in the curriculum design, the learning of how to use technology tools for instructors should be a part of teachers' self-development simultaneously. With a holistic understanding of these MT tools, instructors can well expose learners to the pitfalls of MT tools, so that learners will not use them indiscriminately. However, no matter how fast the technology develop, students' language proficiency can not achieve merely with the help of MT. When there is a challenge, we need to embrace it, but not circumvent it.

\section{References}

ACTFL (2011). ACTFL the Partnership for $21^{\text {st }}$ Century Skills [Electronic version]. Retrieved January 6, 2020, from https://www.actfl.org/sites/default/files/pdfs/21stCenturySkillsMap/p21-worldlanguagemap.pdf

ACTFL. (2017a). ACTFL position statement on the role of technology in language learning [Electronic version]. $\begin{array}{llll}\text { Retrieved January } & 6, & 2020, & \text { from }\end{array}$ https://www.actfl.org/news/position-statements/statement-the-role-technology-language-learning

ACTFL. (2017b). NCSSFL \& ACTFL Can-Do Statements [Electronic version]. Retrieved January 6, 2020, from https://www.actfl.org/publications/guidelines-and-manuals/ncssfl-actfl-can-do-statements

Barrachina, S., Bender, O., Casacuberta, F., Civera, J., Cubel, E., Khadivi, S., ... Vilar, J. M., (2009). Statistical approaches to computer-assisted translation. Comput. Linguist., 35(1), 3-28. https://doi.org/10.1162/coli.2008.07-055-R2-06-29

Casacuberta, F., Civera, J., Cubel, E., Lagarda, A. L., Lapalme, G., Macklovitch, E., \& Vidal, E. (2009). Human interaction for high-quality machine translation. Commun. ACM, 5(10), 135-138. https://doi.org/10.1145/1562764.1562798

Correa, M. (2011). Academic dishonesty in the second language classroom: Instructors' perspectives. Modern Journal of Language Teaching Methods, 1, 65-79. 
Correa, M. (2014). Leaving the "peer" out of peer-editing: Online translators as a pedagogical tool in the Spanish as a second language classroom. Latin American Journal of Content and Language Integrated Learning, 7, 1-20. https://doi.org/10.5294/laclil.2014.7.1.1

Ducar, C., Schocket, D. H. (2018). Machine translation and the L2 classroom: Pedagogical solution for making peace with Google translate. Foreign Language Annals, 51, 779-795. https://doi.org/10.1111/flan.12366

Foster, G., Isabelle, P., \& Plamondon, P. (1997). Target-text mediated interactive machine translation. Mach. Transl., 12, 175-194. https://doi.org/10.1023/A:1007999327580

García, I., \& Pena, M. (2011). Machine translation-assisted language learning: Writing for beginners. Computer Assisted Language Learning, 24, 471-487. https://doi.org/10.1080/09588221.2011.582687

Hutchins, W. J., \& Somers, H. L. (1992). An introduction to machine translation. https://www.hutchinsweb.me.uk/IntroMT-TOC.htm

Kazemi, A., Toral, A., Way, A., Monadjemi, A., \& Nematbakhsh, M. (2017). Syntax- and semantic-based reordering in hierarchical phrased-based statistical machine translation. Expert Systems With Applications, 84, 186-199. https://doi.org/10.1016/j.eswa.2017.05.001

Kazemzadeh, A., \& Kashani, A. (2014). The effect of computer-assisted translation on L2 learners' mastery of writing. International Journal of Research Studies in Language Learning, 3, 29-44. https://doi.org/10.5861/ijrsll.2013.396

Koehn, P., Och, F. J., \& Marcu, D. (2003). Statistical phrase-based translation. In: Proceedings of the Conference of the North American Chapter of the Association for Computational Linguistics on Human Language Technology, 48-54. https://doi.org/10.21236/ADA461156

Larson-Guenette, J. (2013). "It's just reflex now": German language learners' use of online resources. Die Unterrichtspraxis/ Teaching German, 46(1), 62-74. https://doi.org/10.1111/tger.10129

Moussallem, D., Wauer, M., \& Ngomo, A. N. (2018). Machine translation using semantic web technologies: A survey. Web Semantics: Science, Services and Agents on the World Wide Web, 51, 1-19. https://doi.org/10.1016/j.websem.2018.07.001

Newton, D. (2018). It's not liberal arts and literature majors who are most underemployed. Forbes. Retrieved January 6, 2020, from https://www.forbes.com/sites/dereknewton/2018/05/31/its-not-liberal-arts-and-literature-majors-who-are-most-u nderemployed/

Strauss, V. (2017). Analysis: The surprising thing Google learned about its employees--and what it means for today's students. Washington Post. Retrieved January 6, 2020, from https://www.washingtonpost.com/news/answer-sheet/wp/2017/12/20/the-surprising-thing-goole-learned-about-i ts-employees-and-what-it-means-for-todays-students/

White, K. D., \& Heidrich, E. (2013). Our policies, their text: German language students' strategies with and beliefs about Web-based machine translation. Die Unterrichtspraxis/Teaching German, 46(2), 230-250. https://doi.org/10.1111/tger.10143

Williams, L. (2006). Web-based machine translation as a tool for promoting electronic literacy and language awareness. Foreign Language Annuals, 39, 565-578. https://doi.org/10.1111/j.1944-9720.2006.tb02276.x

\section{Copyrights}

Copyright for this article is retained by the author(s), with first publication rights granted to the journal.

This is an open-access article distributed under the terms and conditions of the Creative Commons Attribution license (http://creativecommons.org/licenses/by/4.0/). 